\title{
Virtual Woman: Visits from Words
}

\author{
Cheryl Sourkes
}

\section{Femme virtuelle: visites de mots}

Quand elle lit les femmes dans son trajet, la mémoire coule. Elle commence à imaginer. Elle invente: lettres manquées, mots éffacés, sens perdus, histoires improbables. L'écriture a toujours été inventée à partir de signes pré-existants; la divination, comme l'écriture, désigne une chose à travers une autre. Écriture-divination. Cartes doublées. La profondeur, une ouverture possible. 


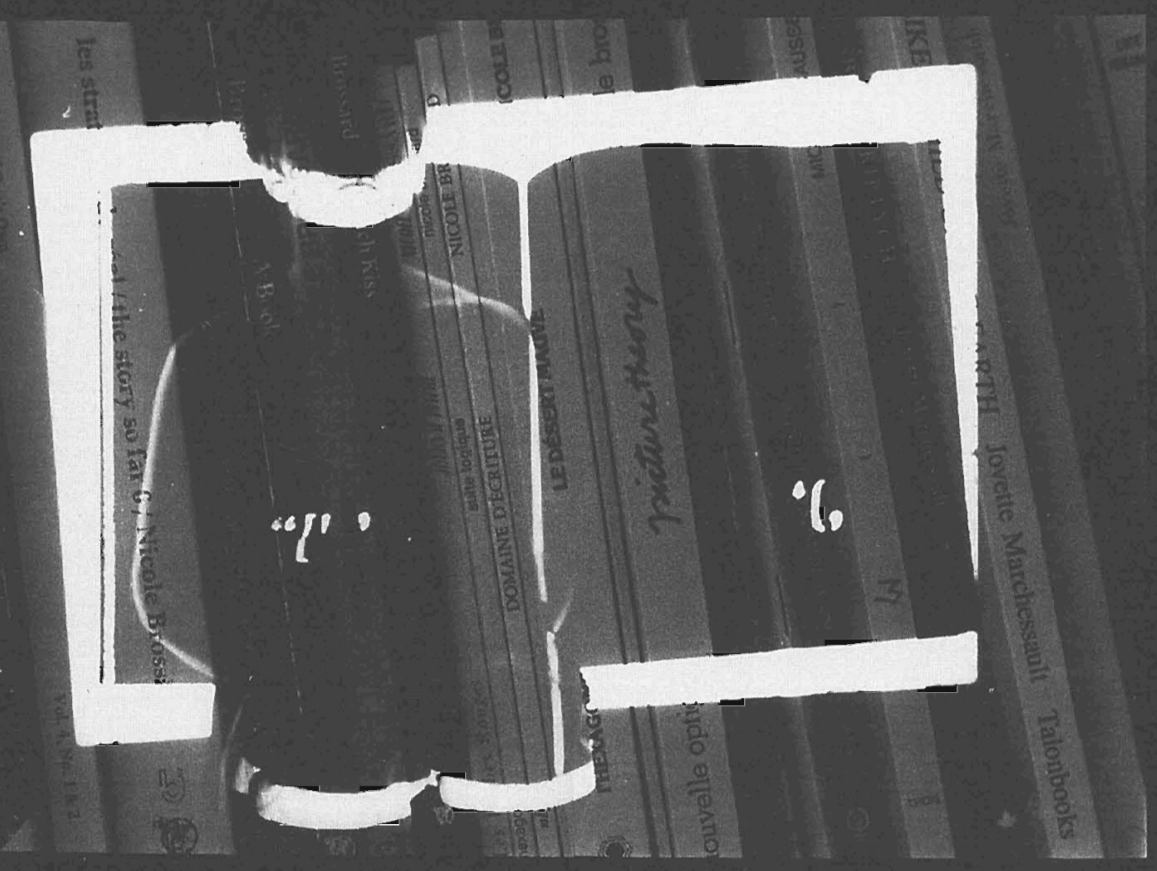


The etymology of writing derives from to scratch or wound.

Reading comes from to interpret.

Psychoanalysis.

When she reads the women in her path, memory lapses, and imagines.

She invents. She formulates.

Missed letters. Dropped words.

Lost meanings. Improbable histories.

She thinks herself an impostor.

Life makes up stories with labile borders.

Her telling unfolds the map

throwing the present into anamorphism.

Embarrassed and suppressed identities.

Textual criticism.

Conversion.

Historically the invention of writing proceeded from the study of preexisting signs.

Bird tracks.

Tracery on sticks and stones.

Shadows. Marks. 


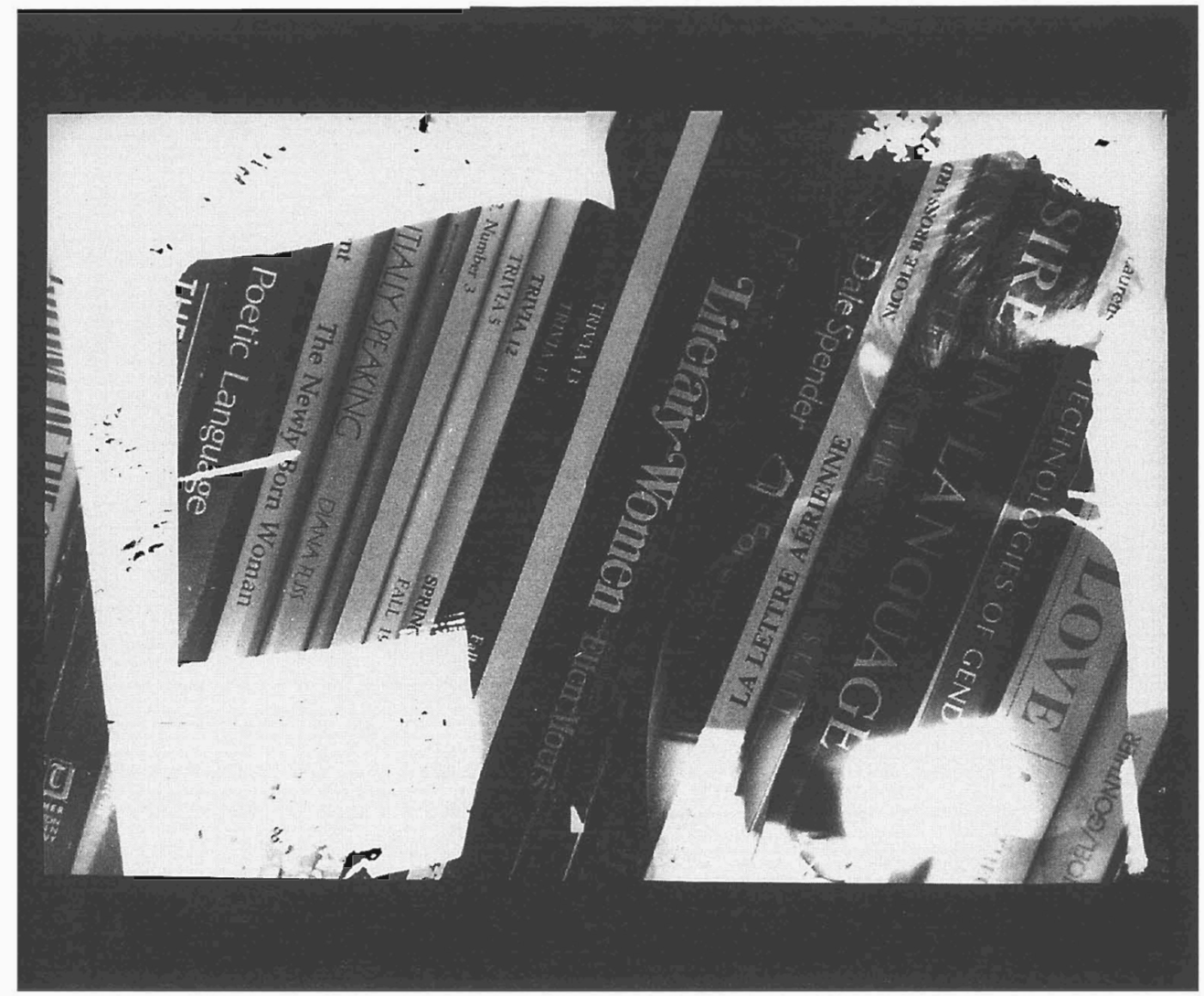


The concept of writing prepares the way for the act of reading.

She (Stein) wrote How To Write in 1931.

He (pound) wrote How to Read in 1944.

She learns about writing

from being written upon.

She learns healing from the co-production of reading.

Details. Clues. Symptoms.

Divinities.

Divinitation, like writing, designates one thing through another.

Twin masks. Coupled maps.

Depth.

The otherworld has a tradition of communicating through signs that appear in the physical realm.

The chance meeting of words.

Divination by means of birds.

The sorceress is one who draws or declares a lot.

Possible opening.

Bio/graphical experimentation.

Thrown light.

Glitter.

She meanders through the annals of history,

dreaming notes into the amnesia/recall oscillation of every age.

Mythology.

Collective thought.

Loose birds. 


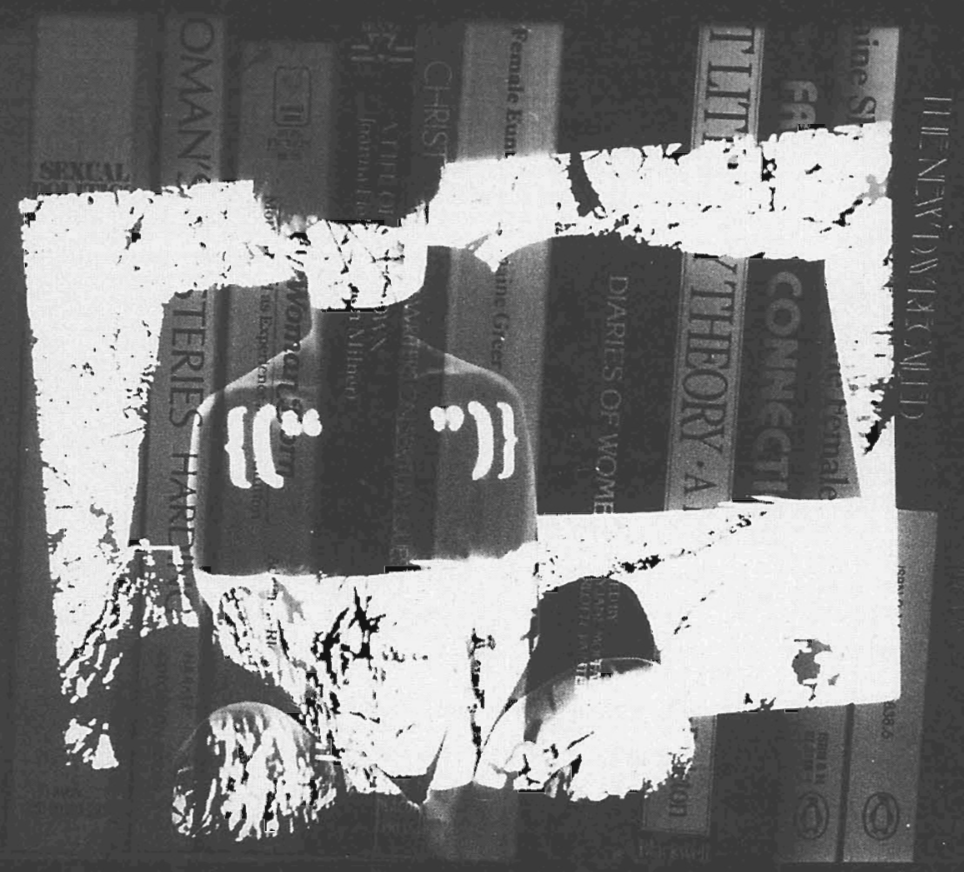

